\title{
Expression of Ras-related protein 25 predicts chemotherapy resistance and prognosis in advanced non-small cell lung cancer
}

\author{
Y.F. Ma*, B. Yang*, J. Li, T. Zhang, J.T. Guo, L. Chen, M. Li, J. Chu, \\ C.Y. Liang and Y. Liu \\ Department of Thoracic Surgery, Chinese PLA General Hospital, Beijing, China \\ *These authors contributed equally to this study. \\ Corresponding author: Y. Liu \\ E-mail: Liuwenliang1959@163.com
}

Genet. Mol. Res. 14 (4): 13998-14008 (2015)

Received March 6, 2015

Accepted June 18, 2015

Published October 29, 2015

DOI http://dx.doi.org/10.4238/2015.October.29.19

\begin{abstract}
Ras-related protein 25 (Rab25) is involved in many human malignancies. However, its role in chemotherapy response and prognosis in advanced non-small cell lung cancer (NSCLC) remains unknown. Therefore, we investigated the relationship between Rab25 and chemotherapy sensitivity and prognosis in NSCLC. Rab25 expression was assessed using immunohistochemistry in 324 advanced NSCLC patients. Its correlations with clinical features were analyzed. Sensitivity to cisplatin (DDP) was compared between DDP-sensitive A549 and DDP-resistant A549/DDP cells. Furthermore, small interfering RNA (siRNA) targeting Rab25 was used for in vitro experiments. Patients with positive Rab25 expression had a significantly lower chemotherapy response rate $(P=0.004)$ and poorer overall survival (OS, $\mathrm{P}=0.0012$ ) than those with negative Rab25 expression. Multivariate analysis indicated that Rab25 expression was an independent prognostic factor for OS $(P=0.016)$. Moreover, Rab25 expression was significantly higher in A549/DDP cells than in A549 cells. Knockdown of Rab25 by siRNA suppressed cell migration and invasion. Cisplatin resistance in A549/DDP cells was also partially reversed by Rab25 silencing. Rab25 expression is
\end{abstract}


a potential prognostic index for advanced NSCLC patients and its inhibition may improve chemosensitization in NSCLC treatment.

Key words: Non-small cell lung cancer; Ras-related protein 25; Chemotherapy response; Prognosis

\section{INTRODUCTION}

Lung cancer is one of the leading causes for cancer-related death worldwide (Kamangar et al., 2006). Non-small cell lung cancer (NSCLC) accounts for up to $85 \%$ of all lung cancer cases (Spira and Ettinger, 2004). Unfortunately, a great number of NSCLC patients are already at an advanced stage by the time of diagnosis, which qualifies them for systemic chemotherapy (Raez and Lilenbaum, 2004). Cisplatin (DDP)-based doublets have been used as the standard first-line chemotherapy for most advanced NSCLC patients (Schiller et al., 2002; Ohe et al., 2007), and have been shown to improve the survival and life quality of NSCLC patients (Jemal et al., 2011). Cisplatin resistance, however, limits the efficacy of chemotherapy in NSCLC (Rosell et al., 2002; Ardizzoni et al., 2007). Therefore, it is critically important to understand the molecular mechanism underlying the development of resistance to chemotherapeutic drugs, particularly platinum-based drugs.

Ras-related protein 25 (Rab25), an intracellular transport protein, belongs to the Rab small GTPase family and is involved in regulating signal transduction and cellular pathways such as cell differentiation and proliferation, vesicle transportation, nuclear assembly, and adhesion and migration of cancer cells (Subramani and Alahari, 2010). It also plays a potential role in the regulation of neoplastic transition (Agarwal et al., 2009). Rab25 overexpression has been reported in colon, liver, and bladder cancers (Goldenring et al., 1993; He et al., 2002; Mor et al., 2003). In addition, studies suggest that Rab25 expression can alter the behavior of breast and ovarian cancer cell lines (Cheng et al., 2004; Caswell et al., 2007). Moreover, overexpression of Rab25 has also been shown to enhance cancer cell proliferation and inhibit apoptosis both in vitro and in vivo (Cheng et al., 2004). However, the clinical significance of Rab25 expression in NSCLC remains unknown. The purpose of the present study was to investigate the expression of Rab25 and its correlation with chemotherapeutic sensitivity and prognosis in cisplatin-based therapy for advanced NSCLC patients. Furthermore, the effect of Rab25 inhibition by small interfering RNA (siRNA) on chemosensitivity, migration, and invasion of NSCLC cells were also analyzed.

\section{MATERIAL AND METHODS}

\section{Patients and samples}

This study was approved by the Chinese PLA General Hospital and all patients gave their informed consent before study commencement. Based on tumor specimen availability, a total of 324 advanced NSCLC patients (stages IIIB and IV) who received cisplatin-based chemotherapy combined with docetaxel, gemcitabine, or vinorelbine at the Department of Thoracic Surgery of our hospital between January 1, 2005 and January 1, 2009 were recruited to take part in this study. All tumor samples were collected before chemotherapy, freshly frozen in liquid nitrogen, and stored at $-80^{\circ} \mathrm{C}$ until required. Clinical stage was assessed based on clinical assessment, chest X-ray, computed tomography of the chest and abdomen, computed tomography or magnetic resonance 
imaging of the brain, and bone scintigraphy. Overall survival (OS) was calculated from the first day of chemotherapy to the day of death or the last day of follow-up.

\section{Treatment and evaluation}

All the patients received at least two rounds of cisplatin-based chemotherapy and additional rounds if the disease progressed. The cisplatin-based regimen included: vinorelbine (25 $\left.\mathrm{mg} / \mathrm{m}^{2}\right)$ on days 1 and 8 plus cisplatin $\left(80 \mathrm{mg} / \mathrm{m}^{2}\right)$ on day 1 of a 21 -day cycle; docetaxel $\left(75 \mathrm{mg} / \mathrm{m}^{2}\right)$ on day 1 plus cisplatin $\left(75 \mathrm{mg} / \mathrm{m}^{2}\right)$ on day 1 of a 21 -day cycle; and gemcitabine $\left(1000 \mathrm{mg} / \mathrm{m}^{2}\right)$ on days 1 and 8 plus cisplatin $\left(80 \mathrm{mg} / \mathrm{m}^{2}\right)$ on day 1 of a 21 -day cycle. The efficacy of the chemotherapy was evaluated based on the Response Evaluation Criteria in Solid Tumors guidelines (Therasse et al., 2000).

\section{Immunohistochemical analysis}

Paraffin-embedded sections (4- $\mu \mathrm{m}$ thick) were deparaffinized, heated in citrate buffer $(\mathrm{pH}$ 6.0), treated with $0.3 \% \mathrm{H}_{2} \mathrm{O}_{2}$, and re-hydrated. After blocking, the sections were incubated with Rab25 antibody (1:100, Santa Cruz, Dallas, TX, USA) in a humidified chamber at room temperature for $1 \mathrm{~h}$. After washing three times with phosphate-buffered saline, the sections were incubated with biotinylated secondary antibody. Subsequently, the slides were rinsed in phosphate-buffered saline, exposed to diaminobenzidine, and counterstained with hematoxylin. After serial dehydration, the slides were mounted for microscopic examination. Negative control sections were prepared using the same staining procedure, leaving the primary antibody blank. The intensity of Rab25 staining was scored as 0,1 , 2, or 3. Percentage scores were assigned as 1: $1-25 \%$; 2 : $26-50 \%$; $3: 51-75 \%$; or $4: 76-100 \%$. The scores for each tumor sample were calculated by multiplying the intensity score with the percentage score to give a final score of 0-12 (Soslow et al., 2000). We then grouped all the samples into a positive expression group (score $\geq 4$ ) or a negative expression group (score between 0 and 3). Two pathologists who were blinded to the clinical data independently graded the staining intensity in all cases.

\section{Cell lines}

Human lung adenocarcinoma cell line A549 cells were obtained from the American Type Culture Collection, and the cisplatin-resistant cell line A549/DDP was obtained from the Xiangya Cell Center, Changsha, China. Both cell lines were maintained in Roswell Park Memorial Institute-1640 medium supplemented with $10 \%$ heat-inactivated fetal bovine serum.

\section{3-(4,5-dimethylthiazol-2-yl)-2,5-diphenyltetrazolium bromide (MTT) assay}

Cell viability was determined by MTT assay. The cells were seeded on 96-well plates at a concentration of $5 \times 10^{3}$ cells per well. After seeding, the cells were exposed to DDP, Rab25 siRNA, or both at indicated time points followed by the addition of $0.5 \mathrm{mg} / \mathrm{mL}$ MTT solution (Sigma-Aldrich, USA) and incubation for $4 \mathrm{~h}$. The medium was then removed and $100 \mathrm{~mL}$ dimethyl sulfoxide was added to each well. The formazan dye crystals were solubilized for $15 \mathrm{~min}$ and the optical density was measured at $405 \mathrm{~nm}$. Cell viability was calculated as a percentage of the control values. 


\section{Western blot}

Logarithmically growing A549 and A549/DDP cells were collected and lysed in lysis buffer on ice. Cell lysates were centrifuged at $10,000 \mathrm{~g}$ for $10 \mathrm{~min}$ at $4^{\circ} \mathrm{C}$, and the protein content in the supernatants was determined using an NSCLC protein assay kit (Pierce, USA). Equal amounts of protein lysates were subjected to electrophoresis separation on $10 \%$ sodium dodecyl sulfate polyacrylamide gel and were transferred to polyvinylidene difluoride membranes (Millipore, USA). The membranes were blocked with $1 \%$ bovine serum albumin for $2 \mathrm{~h}$ at room temperature and incubated with anti-Rab25 antibody (Santa Cruz) or glyceraldehyde 3-phosphate dehydrogenase (GAPDH) (Santa Cruz), followed by incubation with horseradish peroxidaseconjugated secondary antibody. The membrane was then developed and exposed to UV light to determine the optical density. Protein expression levels were quantified using the Quantity One software.

\section{Real-time reverse transcription polymerase chain reaction (RT-PCR)}

Total RNA was extracted using TRIzol (Invitrogen, USA) and quantified by measuring the absorbance at $260 \mathrm{~nm}$. PCR was carried out according to the standard protocol on a Real-Time PCR-system (Applied BioSystems) with SYBR Green detection. After an initial incubation for $10 \mathrm{~min}$ at $95^{\circ} \mathrm{C}, 40$ cycles $\left(95^{\circ} \mathrm{C}\right.$ for $15 \mathrm{~s}, 60^{\circ} \mathrm{C}$ for $1 \mathrm{~min}$, and $72^{\circ} \mathrm{C}$ for $1 \mathrm{~min}$ ) were performed for amplification. The specificity of amplification was confirmed by melting curve analysis. Each sample was tested in triplicate, and results were normalized to the level of GAPDH RNA. The real-time RT-PCR primers for Rab25 and GAPDH are listed as follows: Rab25-F: 5'-TCGCT GAAAA CAATG GACTG CTCTT-3'; Rab25-R: 5'-ATTGG TCCGG ATGCT GTTCT GTCTC T-3'; GAPDH-F: 5'-GAGTC AACGG ATTTG GTCGT-3'. GAPDH-R: 5'-CATGG GTGGA ATCAT ATTGG A-3'.

\section{RNA transfection}

A549 and A549/DDP cells were transfected with 100 nM Rab25 siRNA using Lipofectamine 2000 (Invitrogen) according to the manufacturer instructions. Transfected cells were examined for silencing efficacy $24 \mathrm{~h}$ after transfection.

\section{Cell migration and invasion assays}

The invasive and migratory potency of cells was evaluated by using Transwell inserts with 8- $\mu \mathrm{m}$ pores (BD Biosciences, USA). After 24-h transfection, $3.0 \times 10^{5}$ cells in serum-free medium were loaded into each upper insert, which had been pre-coated with Matrigel matrix (BD Biosciences), for cell invasion assays. The bottom chamber contained standard medium with $10 \%$ fetal bovine serum. After 48-h incubation, non-invasive cells on the upper surface of the filters were removed gently using a cotton-tip swab. Invaded cells on the lower membrane surface were fixed with methanol, stained with $0.1 \%$ crystal violet, and photographed. In the cell migration assays, a similar procedure was used except that $2 \times 10^{5}$ cells were loaded into the inserts with a 24-h incubation without the pre-coated matrix gel. Cell numbers in six randomly selected fields were counted under a light microscope. 


\section{Statistics}

The correlations between Rab25 expression and clinical variables or response to chemotherapy were evaluated by the $x^{2}$-test or the Fisher exact test, where appropriate. KaplanMeier survival curves and the log-rank test were used to analyze univariate distributions for survival. Cox proportional hazards modeling of factors potentially related to survival was performed to identify the effects on survival. $\mathrm{P}<0.05$ was considered to be statistically significant. All analyses were performed with the SPSS 16.0 software.

\section{RESULTS}

\section{Correlation of Rab25 expression with clinicopathological features or response to cisplatin-based chemotherapy in NSCLC patients}

As shown in Figure 1, Rab25 staining was mainly localized in the cytoplasm but not in the nucleus. The positive expression rate of Rab25 protein was $71.6 \%(232 / 324)$ in NSCLC but only $14.5 \%(47 / 324)$ in adjacent normal tissue and the result was statistically significant $(P<0.001)$. The correlation between Rab25 expression and the clinicopathological features is shown in Table 1. The cisplatin-based chemotherapy response rate of patients with Rab25-positive expression was $30 \%$, as opposed to $52 \%$ for patients with Rab25-negative expression, suggesting Rab25 expression was associated with response to cisplatin-based chemotherapy $(P=0.004$, Table 1$)$.

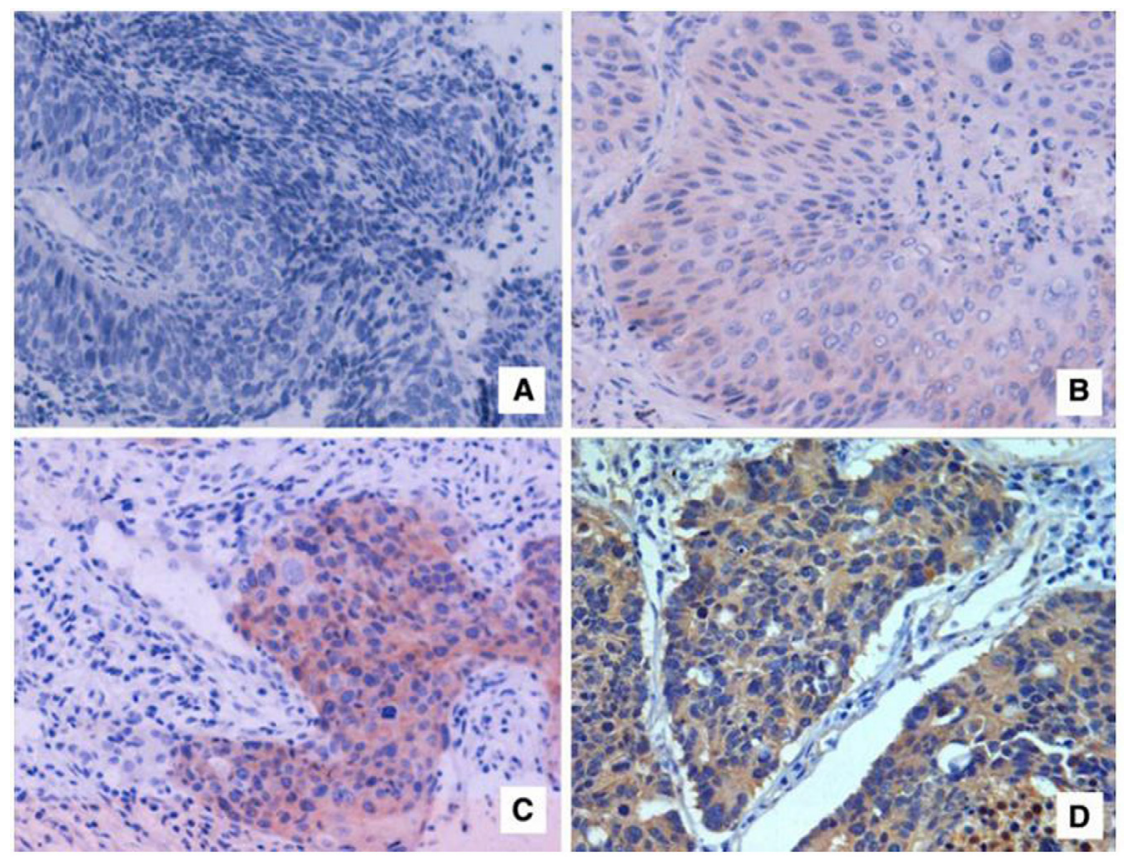

Figure 1. Immunohistochemical analysis of Rab25 expression in non-small cell lung cancer (NSCLC). A. No expression of Rab25 in NSCLC. B. Weak staining arising from low Rab25 expression in NSCLC. C. Moderate staining. D. Strong staining (magnification 400X). 


\begin{tabular}{|c|c|c|c|c|}
\hline \multirow[t]{2}{*}{ Characteristic } & \multirow[t]{2}{*}{$N$} & \multicolumn{2}{|c|}{ Rab25 expression } & \multirow[t]{2}{*}{$P$} \\
\hline & & Negative & Positive & \\
\hline Age & & & & 0.583 \\
\hline$\leq 60$ & 178 & 45 & 133 & \\
\hline$>60$ & 146 & 47 & 99 & \\
\hline Gender & & & & 0.690 \\
\hline Female & 116 & 36 & 80 & \\
\hline Male & 208 & 56 & 152 & \\
\hline Histological type & & & & 0.532 \\
\hline Adenocarcinoma & 132 & 40 & 92 & \\
\hline Others & 192 & 52 & 140 & \\
\hline Stage & & & & 0.302 \\
\hline IIIB & 132 & 43 & 89 & \\
\hline IV & 192 & 49 & 143 & \\
\hline Smoking status & & & & 0.714 \\
\hline Non-smoker & 139 & 41 & 98 & \\
\hline Smoker & 185 & 51 & 134 & \\
\hline Chemotherapy regimens & & & & 0.853 \\
\hline DDP + GEM & 104 & 32 & 72 & \\
\hline $\mathrm{DDP}+\mathrm{TXT}$ & 84 & 22 & 62 & \\
\hline $\mathrm{DDP}+\mathrm{NVB}$ & 136 & 38 & 98 & \\
\hline Chemotherapy response & & & & 0.004 \\
\hline$C R+P R$ & 118 & 48 & 70 & \\
\hline$S D+P D$ & 206 & 44 & 162 & \\
\hline
\end{tabular}

\section{Correlation of Rab25 expression with prognosis for NSCLC patients}

The OS curves calculated by the Kaplan-Meier method according to Rab25 expression are shown in Figure 2. Rab25 expression was significantly associated with OS ( $P=0.0012$, Table 2), and the median OS time was 17.1 months for the Rab25-negative group and 10.6 months for the Rab25-positive group (Table 2). Independent of all the other variables being evaluated, the multiple Cox regression model showed that the positive expression of Rab25 was an independent factor for predicting poor OS in patients with advanced NSCLC (relative risk: 1.512, P = 0.016) (Table 3 ).

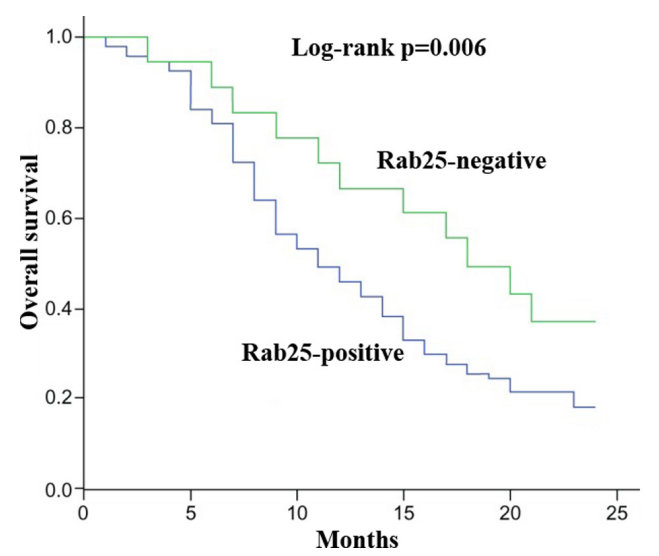

Figure 2. Association between Rab25 expression and non-small cell lung cancer (NSCLC) patient survival. Patients with positive Rab25 expression exhibited a significantly shorter survival time than those with negative Rab25 expression. 
Table 2. Univariate analysis for overall survival in non-small cell lung cancer (NSCLC) patients.

\begin{tabular}{|c|c|c|}
\hline Characteristic & Median OS (95\%Cl, months) & $\mathrm{P}$ \\
\hline Age & & 0.408 \\
\hline$\leq 60$ & $11.6(8.721-15.906)$ & \\
\hline$>60$ & $10.6(7.547-13.978)$ & \\
\hline Gender & & 0.197 \\
\hline Female & $11.2(7.941-14.659)$ & \\
\hline Male & $10.7(7.552-14.048)$ & \\
\hline Histological type & & 0.231 \\
\hline Adenocarcinoma & $11.4(8.016-14.584)$ & \\
\hline Others & $10.9(7.343-14.257)$ & \\
\hline Stage & & 0.198 \\
\hline IIIB & $11.7(5.756-17.444)$ & \\
\hline IV & $11.2(8.408-13.792)$ & \\
\hline Smoking status & & 0.144 \\
\hline Non-smoker & $12.5(6.741-18.459)$ & \\
\hline Smoker & $10.7(7.823-13.177)$ & \\
\hline Chemotherapy regimens & & 0.621 \\
\hline DDP + GEM & $11.5(5.793-17.807)$ & \\
\hline $\mathrm{DDP}+\mathrm{TXT}$ & $11.0(6.206-15.994)$ & \\
\hline $\mathrm{DDP}+\mathrm{NVB}$ & $10.6(7.168-13.832)$ & \\
\hline Chemotherapy response & & 0.301 \\
\hline$C R+P R$ & $13.3(9.544-16.856)$ & \\
\hline$S D+P D$ & $10.4(7.307-13.093)$ & \\
\hline Rab25 & & 0.0012 \\
\hline Negative & $17.1(10.508-24.312)$ & \\
\hline Positive & $10.6(7.825-13.195)$ & \\
\hline
\end{tabular}

OS = overall survival; $\mathrm{Cl}$ = confidence interval; DDP = cisplatin; GEM = gemcitabine; $\mathrm{TXT}$ = docetaxel; NVB = vinorelbine; $\mathrm{CR}=$ complete response; $\mathrm{PR}=$ partial response; $\mathrm{SD}=$ stable disease; $\mathrm{PD}=$ progressive disease. $\mathrm{NSCLC}=$ non-small-cell lung cancer.

\begin{tabular}{|c|c|c|}
\hline & $\mathrm{RR}(95 \% \mathrm{Cl})$ & $\mathrm{P}$ \\
\hline \multicolumn{3}{|l|}{ Age } \\
\hline$\leq 60$ & 1.000 & \multirow[t]{2}{*}{0.315} \\
\hline$>60$ & $1.193(0.861-1.684)$ & \\
\hline \multicolumn{3}{|l|}{ Gender } \\
\hline Female & 1.000 & \multirow[t]{2}{*}{0.709} \\
\hline Male & $1.072(0.618-1.867)$ & \\
\hline \multicolumn{3}{|l|}{ Histological type } \\
\hline Adenocarcinoma & 1.000 & \multirow[t]{2}{*}{0.877} \\
\hline Others & $1.047(0.584-1.879)$ & \\
\hline \multicolumn{3}{|l|}{ Stage } \\
\hline IIIB & 1.000 & \multirow[t]{2}{*}{0.372} \\
\hline IV & $1.175(0.825-1.675)$ & \\
\hline \multicolumn{3}{|l|}{ Smoking status } \\
\hline Non-smoker & 1.000 & \multirow[t]{2}{*}{0.509} \\
\hline Smoker & $1.149(0.761-1.733)$ & \\
\hline \multicolumn{3}{|c|}{ Chemotherapy regimens } \\
\hline DDP + GEM & 1.000 & 0.965 \\
\hline $\mathrm{DDP}+\mathrm{TXT}$ & $0.990(0.627-1.564)$ & \multirow[t]{2}{*}{0.427} \\
\hline $\mathrm{DDP}+\mathrm{NVB}$ & $1.168(0.797-1.712)$ & \\
\hline \multicolumn{3}{|c|}{ Chemotherapy response } \\
\hline$C R+P R$ & 1.000 & \multirow[t]{2}{*}{0.566} \\
\hline$S D+P D$ & $1.112(0.774-1.598)$ & \\
\hline \multicolumn{3}{|l|}{ Rab25 } \\
\hline Negative & 1.000 & \multirow[t]{2}{*}{0.016} \\
\hline Positive & $1.512(1.038-2.985)$ & \\
\hline
\end{tabular}

$\mathrm{RR}=$ relative risk; $\mathrm{Cl}$ = confidence interval; DDP = cisplatin; GEM = gemcitabine; $\mathrm{TXT}$ = docetaxel; NVB = vinorelbine; $\mathrm{CR}=$ complete response; $\mathrm{PR}=$ partial response; $\mathrm{SD}=$ stable disease $; \mathrm{PD}=$ progressive disease. 


\section{Rab25 upregulation in DDP-resistant cancer cells}

A549 and A549/DDP cells were treated with different concentrations of cisplatin for 24 or $48 \mathrm{~h}$. Cell growth inhibition was then evaluated by MTT assay. Although cisplatin inhibited the proliferation of both cell lines, A549 cells were more sensitive to cisplatin treatment than A549/DDP cells (Figure $3 \mathrm{~A}$ ).

To investigate whether Rab25 mRNA expression affects cisplatin resistance, real time RTPCR and western blot analyses were performed. Expression levels of Rab25 mRNA and protein in A549/DDP were significantly higher than in A549 (Figure 3B and C). These results collectively indicate that Rab25 might be related to cisplatin resistance in A549/DDP cells.
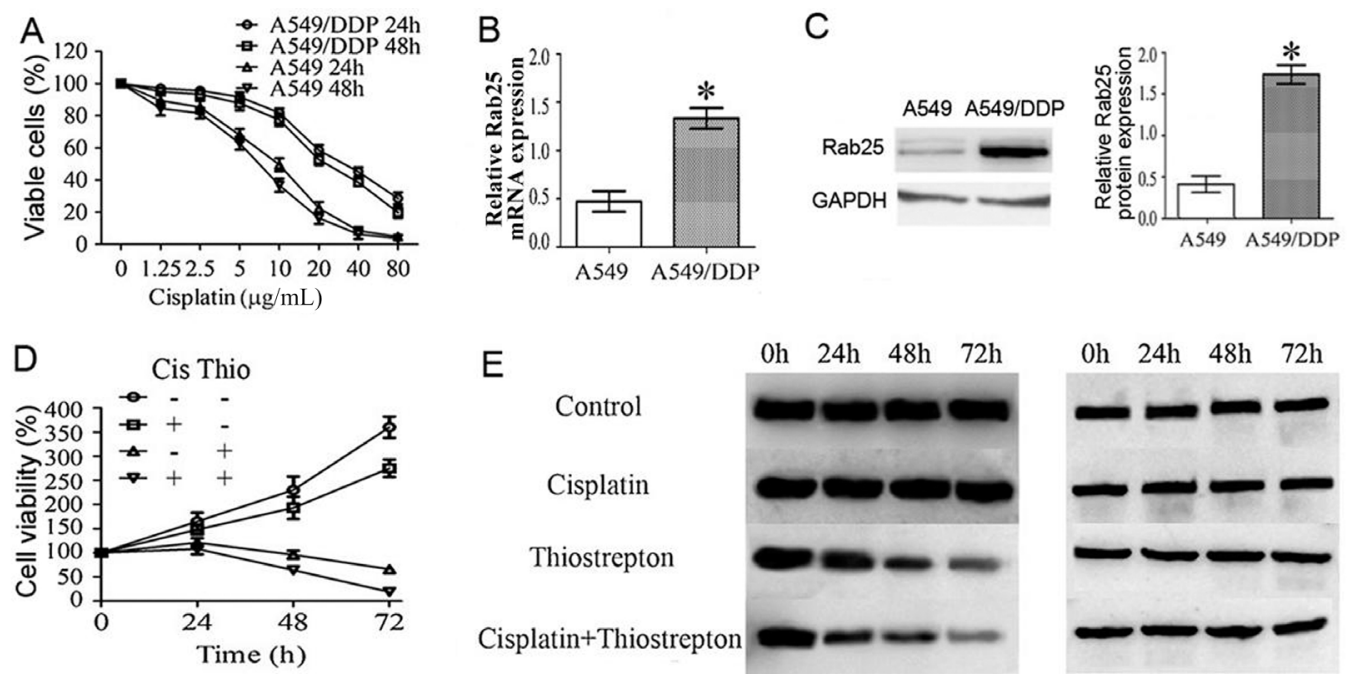

Figure 3. Cisplatin-resistant cell line showed elevated Rab25 mRNA and protein expression levels, and thiostrepton overcame cisplatin resistance in A549/DDP cells. A. A549 and A549/DDP cells were treated with various concentrations of cisplatin for 24 and $48 \mathrm{~h}$. Cell viability was determined by 3-(4,5-dimethylthiazol-2-yl)-2,5-diphenyltetrazolium bromide (MTT) assays. B. Analysis of Rab25/GAPDH mRNA expression in A549 and A549/DDP cells by real-time reverse transcription polymerase chain reaction (RT-PCR) (GAPDH is glyceraldehyde 3-phosphate dehydrogenase). C. Western blot analysis of Rab25/GAPDH protein expression levels in A549 and A549/DDP cells. D. MTT assays of A549/DDP cells with $2 \mu \mathrm{g} / \mathrm{mL}$ cisplatin. The percentage of viable cells at each time point is shown. E. A549/DDP cell lysates were analyzed by western blot. Data are reported as means $\pm S D$. ${ }^{*} P<0.05$.

\section{Inhibition of Rab25 expression by siRNA}

As shown in Figure 4A-C, transfection with Rab25 siRNA resulted in efficient knockdown of Rab25 mRNA expression and protein levels $(P<0.05)$, suggesting that siRNA targeting of Rab25 can effectively inhibit the expression of Rab25 in NSCLC cells. To determine the effect of siRNA-mediated Rab25 inhibition on the sensitivity of A549/DDP and A549 cells, MTT assays were performed to determine the cell viability. After transfection, A549/DDP and A549 cells were exposed to various concentrations of cisplatin for $24 \mathrm{~h}$. The results showed that siRNA-mediated Rab25 inhibition resulted in a marked decrease in cell viability (Figure 4D and E). 

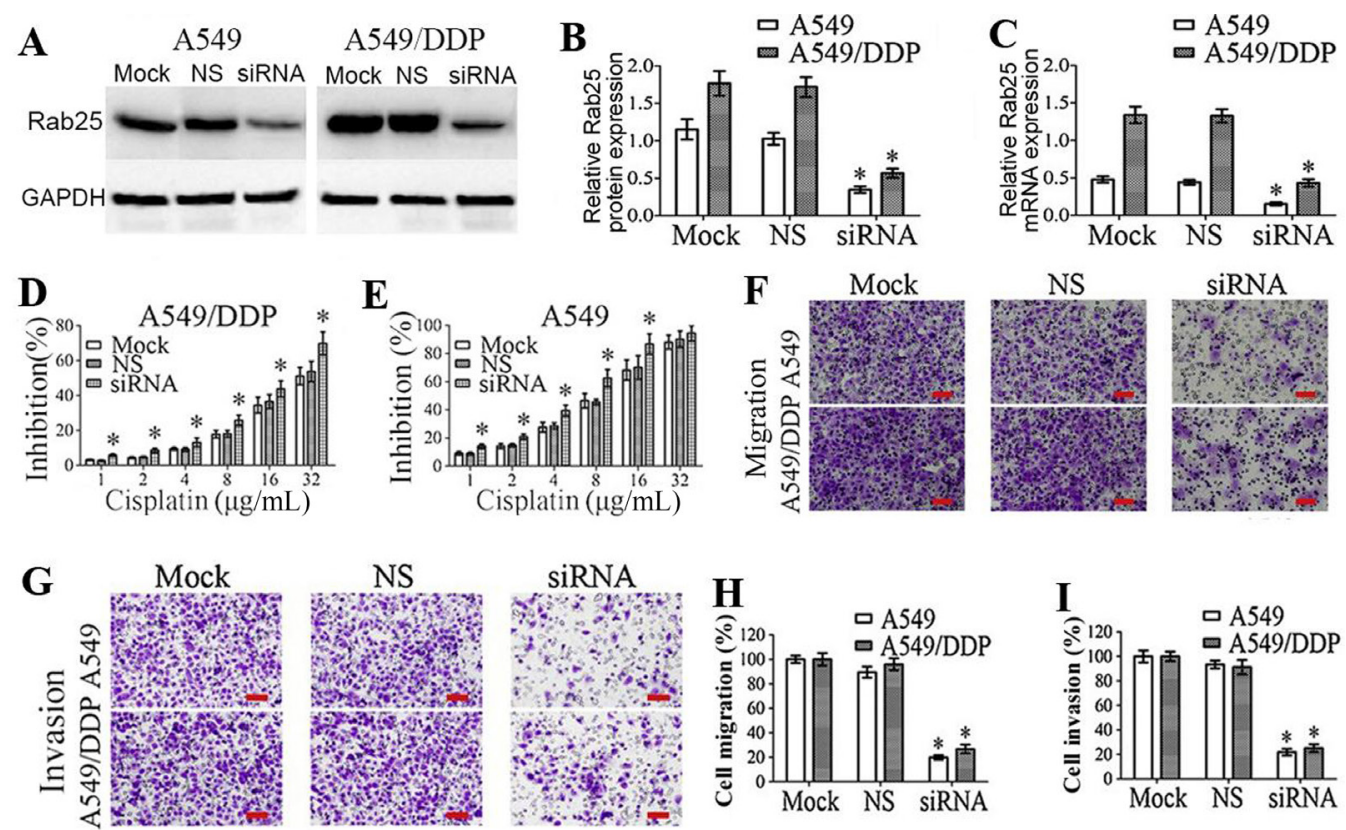

Figure 4. Effect of Rab25 silencing on the migration and invasion ability of A549 and A549/DDP cells in vitro. Cisplatin resistance in A549/DDP cells was partially reversed through Rab25 silencing. A549 and A549/DDP cells were untransfected (mock), transfected with nonspecific (NS) control small interfering RNA (siRNA) (100 nM), or siRNA against Rab25 (100 nM) for 24 h. A. Analysis of Rab25 expression level in A549 and A549/DDP cells by western blot. B. Rab25 protein expression levels in both cell lines were significantly decreased by Rab25 siRNA transfection. C. Real-time reverse transcription polymerase chain reaction (RT-PCR) analysis to determine the relative Rab25 mRNA level. D.-G. Silencing of Rab25 dramatically reduced A549 and A549/DDP cell migration and invasion in vitro. Scale bars $=0.1 \mathrm{~mm}$. H. and I. Rab25 siRNA-transfected A549 and A549/ DDP cells had higher inhibition rates than the mock-transfected cells and controls. Data are reported as means \pm SD for three independent experiments. ${ }^{*} \mathrm{P}<0.05$.

\section{Effects of Rab25 siRNA on cell migration and invasion}

We performed siRNA transfection to further examine the effects of Rab25 downregulation on cell migration and invasion in A549 and A549/DDP cells. Our data showed that migration and invasion in both cell lines transfected with Rab25 siRNA were significantly inhibited compared with those cells transfected with nonspecific siRNA (Figure 4F-I), indicating that Rab25 is involved in cell migration and invasion.

\section{DISCUSSION}

In the present study, we explored the role of Rab25 expression in human NSCLC. We found, for the first time, that Rab25 expression was significantly elevated in NSCLC patients.

More importantly, patients with positive Rab25 expression had a significantly lower chemotherapy response rate and poorer overall survival than those with negative expression. Multivariate analyses indicated that Rab25 expression was an independent prognostic factor for OS in NSCLS patients. Furthermore, our in vitro studies showed that suppression of Rab25 significantly inhibited cell migration and invasion of A549 and A549/DDP cells. Cisplatin resistance 
in A549/DDP cells was partially reversed by Rab25 silencing. These findings suggest that Rab25 might be a novel therapeutic target in NSCLC patients and Rab25 inhibition could be a potential strategy for improving chemosensitization of NSCLC cells.

It has been clearly shown that Rab25 can affect epithelial cell transformation (Goldenring and Nam, 2011) through its regulation of the membrane-trafficking system that changes the polarity of epithelial cells and directs the localization of integrin-recycling vesicles to enhance the cell invasive ability (Caswell et al., 2007). This suggests that Rab25 may potentially play an important role in oncogenesis. Wang et al. (2002) reported that Rab25 expression was elevated in a metastatic breast cancer cell line. We also investigated the role of Rab25 in cell migration and invasion, and suggest that knockdown of Rab25 suppresses cell migration and invasion of A549 and A549/DDP cells. Our results show that Rab25 may be a potential drug target for treating NSCLC.

We also examined the relationships between Rab25 protein expression and resistance or prognosis after cisplatin-based chemotherapy in advanced NSCLC patients. We found that Rab25 expression was significantly associated with poor response to cisplatin-based chemotherapy and unfavorable prognosis. The Cox proportional hazard model analysis showed that Rab25 expression was an independent prognostic factor for OS. These findings suggest that Rab25 may regulate cisplatin-based chemotherapy resistance in advanced NSCLC, although the underlying mechanism remains unclear. Our in vitro studies confirmed that Rab25 overexpression is associated with cisplatin resistance. Further investigations are required to clarify the mechanism of Rab25 in regulating chemoresistance in advanced NSCLC patients.

Cisplatin is one of the most widely used drugs in treating NSCLC. Unfortunately, chemoresistance remains a significant challenge, impeding its clinical application. Therefore, identification of novel predictive markers for evaluating the response to cisplatin treatment may be helpful for the development of personalized treatment to further improve treatment efficacy and minimize side effects. In this study, we chose A549 cells and their cisplatin-resistant counterparts, A549/DDP cells, as in vitro models to examine the mechanism of cisplatin resistance. We found that Rab25 expression in terms of both mRNA and protein levels was significantly increased in A549/DDP cells in comparison with the parental cells. Furthermore, after transfection with Rab25specific siRNA, the Rab25 mRNA and protein expression levels were significantly suppressed in the A549 and A549/DDP cell lines. The MTT results showed that drug resistance decreased in the transfected group, indicating that Rab25 knockdown can enhance the chemosensitivity of A549 and A549/DDP cells to cisplatin. We also found that Rab25 silencing significantly repressed cell migration and invasion in A549 and A549/DDP cells.

Taken together, these finding suggest that positive Rab25 expression predicts an unfavorable prognosis and insensitivity to cisplatin-based chemotherapy in advanced NSCLC patients. Therefore, Rab25 is an important regulator of cisplatin-based chemotherapy resistance in advanced NSCLC and may provide novel therapeutic targets in the treatment of cisplatin-resistant NSCLC.

\section{Conflicts of interest}

The authors declare no conflict of interest.

\section{ACKNOWLEDGMENTS}

We thank the anonymous reviewers for reviewing this manuscript. 


\section{REFERENCES}

Agarwal R, Jurisica I, Mills GB and Cheng KW (2009). The emerging role of the RAB25 small GTPase in cancer. Traffic 10: 1561-1568.

Ardizzoni A, Boni L, Tiseo M, Fossella FV, et al. (2007). Cisplatin- versus carboplatin-based chemotherapy in first-line treatment of advanced non-small-cell lung cancer: an individual patient data meta-analysis. J. Natl. Cancer Inst. 99: 847-857.

Caswell PT, Spence HJ, Parsons M, White DP, et al. (2007). Rab25 associates with alpha5beta1 integrin to promote invasive migration in 3D microenvironments. Dev. Cell 13: 496-510.

Cheng KW, Lahad JP, Kuo WL, Lapuk A, et al. (2004). The RAB25 small GTPase determines aggressiveness of ovarian and breast cancers. Nat. Med. 10: 1251-1256.

Goldenring JR and Nam KT (2011). Rab25 as a tumour suppressor in colon carcinogenesis. Br. J. Cancer 104: 33-36.

Goldenring JR, Shen KR, Vaughan HD and Modlin IM (1993). Identification of a small GTP-binding protein, Rab25, expressed in the gastrointestinal mucosa, kidney, and lung. J. Biol. Chem. 268: 18419-18422.

$\mathrm{He} \mathrm{H}$, Dai F, Yu L, She X, et al. (2002). Identification and characterization of nine novel human small GTPases showing variable expressions in liver cancer tissues. Gene Expr. 10: 231-242.

Jemal A, Bray F, Center MM, Ferlay J, et al. (2011). Global cancer statistics. CA Cancer J. Clin. 61: 69-90.

Kamangar F, Dores GM and Anderson WF (2006). Patterns of cancer incidence, mortality, and prevalence across five continents: defining priorities to reduce cancer disparities in different geographic regions of the world. J. Clin. Oncol. 24: 2137-2150.

Mor O, Nativ O, Stein A, Novak L, et al. (2003). Molecular analysis of transitional cell carcinoma using cDNA microarray. Oncogene 22: 7702-7710.

Ohe Y, Ohashi Y, Kubota K, Tamura T, et al. (2007). Randomized phase III study of cisplatin plus irinotecan versus carboplatin plus paclitaxel, cisplatin plus gemcitabine, and cisplatin plus vinorelbine for advanced non-small-cell lung cancer: FourArm Cooperative Study in Japan. Ann. Oncol. 18: 317-323.

Raez LE and Lilenbaum R (2004). Chemotherapy for advanced non-small-cell lung cancer. Clin. Adv. Hematol. Oncol. 2: 173-178.

Rosell R, Lord RV, Taron M and Reguart N (2002). DNA repair and cisplatin resistance in non-small-cell lung cancer. Lung Cancer 38: 217-227.

Schiller JH, Harrington D, Belani CP, Langer C, et al. (2002). Comparison of four chemotherapy regimens for advanced nonsmall-cell lung cancer. N. Engl. J. Med. 346: 92-98.

Soslow RA, Dannenberg AJ, Rush D, Woerner BM, et al. (2000). COX-2 is expressed in human pulmonary, colonic, and mammary tumors. Cancer 89: 2637-2645.

Spira A and Ettinger DS (2004). Multidisciplinary management of lung cancer. N. Engl. J. Med. 350: 379-392.

Subramani D and Alahari SK (2010). Integrin-mediated function of Rab GTPases in cancer progression. Mol. Cancer 9: 312.

Therasse P, Arbuck SG, Eisenhauer EA, Wanders J, et al. (2000). New guidelines to evaluate the response to treatment in solid tumors. European Organization for Research and Treatment of Cancer, National Cancer Institute of the United States, National Cancer Institute of Canada. J. Natl. Cancer Inst. 92: 205-216.

Wang W, Wyckoff JB, Frohlich VC, Oleynikov Y, et al. (2002). Single cell behavior in metastatic primary mammary tumors correlated with gene expression patterns revealed by molecular profiling. Cancer Res. 62: 6278-6288. 